\title{
Long-term changes in autumn migration dates at the Strait of Gibraltar reflect population trends of soaring birds
}

\author{
MICHELE PANUCCIO, ${ }^{1, *}$ BEATRIZ MARTÍN, ${ }^{2}$ MICHELANGELO MORGANTI, ${ }^{3}$ ALEJANDRO ONRUBIA ${ }^{2}$ \& \\ MIGUEL FERRER ${ }^{2,4}$ \\ ${ }^{1}$ MEDRAPTORS (Mediterranean Raptor Migration Network), via Mario Fioretti 18, 00152 Rome, Italy \\ ${ }^{2}$ Fundación Migres, Ctra. N-340, Km. 96.7, Huerta Grande, Pelayo, Algeciras, E-11390 Cádiz, Spain \\ ${ }^{3}$ Section of Animal Biology, Department STEBICEF, University of Palermo, Via Archirafi 18, 90123 Palermo, Italy \\ ${ }^{4}$ Ethology and Biodiversity Conservation, Doñana Biological Station, CSIC, c/ Américo Vespucio s/n, \\ E-41092 Seville, Spain
}

A growing body of work shows that climate change is the cause of a number of directional shifts in the spring phenology of migratory birds. However, changes in autumn phenology are well studied and their consistency across species, as well as their link with population trends, remains uncertain. We investigate changes in the autumn migration dates of 11 species of soaring birds over the Strait of Gibraltar over a 16-year period. Using models corrected for phylogeny, we assessed whether ecological and morphological characteristics, as well as population trends, account for interspecific shifts in migration times. We recorded different phenological changes in different periods of the migration season and suggest that these differences are due to age-dependent responses. The variable best predicting advances in migration dates was population trend: species that did not advance their autumn migration dates were those showing a decline in their European breeding populations. We repeated our tests on a dataset representing the migration date of soaring birds across the Pyrenees Mountains and found that population trends at this site also predicted phenological shifts. Our results suggest that flexibility in migratory strategy and population trends may be related, such that different adaptive capacity in migration timing may be more relevant than other ecological traits in determining the conservation status of migratory birds in Europe and perhaps other regions.

Keywords: adaptation, climate change, phenological shift, plastic responses, population trend, soaring migrants.

In recent decades spring events such as flowering, leaf appearance and insect emergence have been occurring earlier as a result of climate change (e.g. Parmesan \& Yohe 2003). This leads to a mismatch between timing of breeding and timing of peak prey availability for many migratory bird species (Both 2007) and is imposing strong selective pressure on their optimal arrival dates at breeding territories (Kokko 1999, Møller 2007, Gienapp et al. 2008). To cope with this new environment, changes in migratory behaviour under the

*Corresponding author.

Email: panucciomichele@gmail.com influence of climate change have become evident in populations of a wide range of bird species at many sites in the Northern Hemisphere (Both \& Marvelde 2007, Knudsen et al. 2011). Among these changes, shifts in arrival and departure dates have been detected in many migratory species (Fiedler et al. 2004, Schaefer et al. 2008, Visser et al. 2009, Knudsen et al. 2011). Earlier spring arrival dates of long-distance European migrants have been reported in response to climate change (Gordo 2007). However, studies predicting the direction and magnitude of changes experienced in autumn migration timing are less clear, with some species advancing and others delaying their 
autumn migration (Jenni \& Kéry 2003, Lehikoinen et al. 2004, Filippi-Codaccioni et al. 2010, Jaffré et al. 2013).

Most studies assessing phenological shifts have focused on small, short-lived birds (primarily passerines) as model species (Jenni \& Kéry 2003, Jonzén et al. 2006, Tøttrup et al. 2006, Rubolini et al. 2007, Knudsen et al. 2011). Our understanding of the effects of climate change on soaring birds remains largely unexplored (Filippi-Codaccioni et al. 2010, Jaffré et al. 2013, Martín et al. 2014) and phenological changes in soaring birds have rarely been studied in detail (but see Filippi-Codaccioni et al. 2010, Jaffré et al. 2013). Species-specific characteristics related to general ecology and life-history traits are important factors that may mediate the impact of climate change and its effects on the timing in response of migration (Jenni \& Kéry 2003), and may explain interspecific differences in response to climate change (Rubolini et al. 2007). Whereas short-distance migrants can, when necessary, adjust migration timing to regional weather conditions at their destination (Miller-Rushing et al. 2008, Visser et al. 2009, Jaffré et al. 2013), long-distance migrants are considered to be constrained by endogenous factors (Gwinner 1996), as they are probably unaware of conditions in the arrival areas (Lehikoinen et al. 2004). However, the migration timing of some long-distance migrants may not be as constrained as previously thought (Both 2007, Scholer et al. 2016). As long-lived species, soaring birds are expected to be able to learn (Sergio et al. 2014) and therefore they might be able to adjust their behaviour as a result of prevailing conditions to a greater extent than smaller birds with a shorter life expectancy.

In this study, we relied on a long-term dataset (16 years; Møller \& Fiedler 2010) of visually detected migrants recorded during autumn at the Strait of Gibraltar. We assessed shifts in migratory dates of raptors and storks passing across the western African-Palaearctic flyway and assessed whether the shifts were species-specific. Furthermore, we assessed whether variability in ecological, behavioural, morphological and life-history traits, as well as European-scale population trends, predicted intra-specific differences in the shift of the migratory dates. The possibility that different phases of migration (onset, midpoint and end) had different phenological shifts was also considered, as well as the possibility that individuals belonging to different age or sex classes might shift their migratory dates differently. Together with the data collected at the Strait of Gibraltar, we analysed phenological shifts at an additional focal site along the western migration route in the Western Palaearctic at Organbidexka, France (Porter \& Beaman 1985, Finlayson 1992, Filippi-Codaccioni et al. 2010), to check for the consistency of the factors affecting phenological shifts along the same flyway.

\section{METHODS}

\section{Study area and data collection}

The Strait of Gibraltar in southern Europe and northern Africa is the main bottleneck where raptors and storks breeding in western Europe are funnelled to cross the Mediterranean Sea during migration (Finlayson 1992, Hake et al. 2003, Meyburg et al. 2004, Limiñana et al. 2007, Programa Migres 2009, Klaassen et al. 2010, Panuccio et al. 2014). We used a dataset comprising 16 years of autumn migration counts covering the period 1999-2014. For all years, counts were conducted with a standardized protocol during the post-breeding migration from mid-July to mid-October (Martín et al. 2016a,b,). For each bird visually detected, we assigned cardinal values to define their direction of origin and destination. We only included individuals in analyses where they were assigned a southern trajectory (i.e. indicating they were attempting to cross the Strait) to minimize the possibility of overestimating the number of birds migrating. Counts were not conducted on days with persistent precipitation or when wind speeds exceeded 6 on the Beaufort scale. Two coastal watchpoints were used simultaneously: Algarrobo $\left(36^{\circ} 5^{\prime} 25^{\prime \prime} \mathrm{N}, 5^{\circ} 29^{\prime} 02^{\prime \prime} \mathrm{W}\right)$ which is situated near the town of Algeciras, and Cazalla $\left(36^{\circ} 1^{\prime} 58^{\prime \prime} \mathrm{N}\right.$, $5^{\circ} 34^{\prime} 36^{\prime \prime} \mathrm{W}$ ) located closer to the Atlantic (Fig. 1).

To reach statistically representative samples at the specific level, we limited our analyses to the set of species with the highest autumn migration counts through the Strait (Programa Migres 2009), ultimately including nine species of Accipitriformes and two species of storks. Most of the species considered are long-distance migrants and, with the exception of a small proportion of individuals that winter in Morocco, birds crossing the Strait of Gibraltar are expected to spend the winter in sub-Saharan Africa (Ferguson-Lees \& Christie 2001). The average annual count ( \pm se) over the study period was $259.381 \pm 15.161$ individuals across all the species investigated here. 


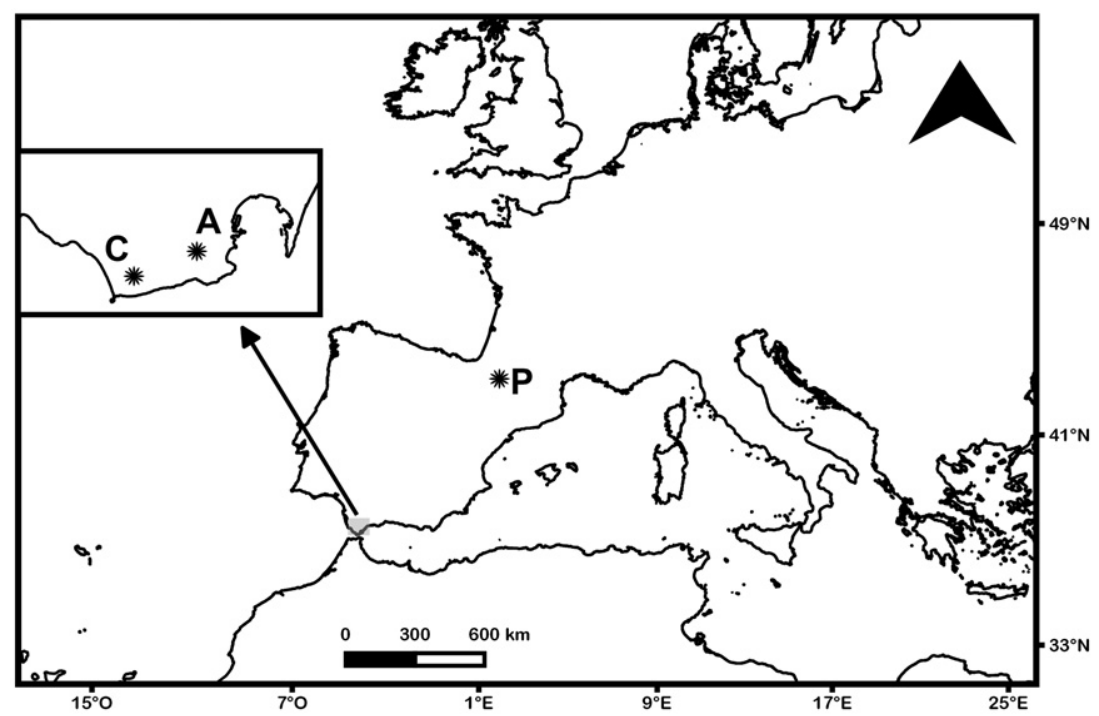

Figure 1. Study area. Watchsites along the western migration route in the Western Palaearctic where counts were conducted ( $P=$ Pyrenees; $C=$ Cazalla; $A=A l g a r r o b o)$. At the Strait of Gibraltar, both sites recorded north-south orientated movements of soaring birds passing through the site in autumn.

\section{Statistical analysis}

\section{Quantile regression}

In studies assessing changes in bird migratory phenology, the use of first appearance dates as response variables has attracted criticism (MillerRushing et al. 2008). Moreover, it is known that our set of species may show a bimodal peak of migratory passage, due to differential timing of individuals belonging to different populations and/ or different age and sex classes (Finlayson 1992). We therefore used quantile regression $(\mathrm{QR})$ to study the shift of different phases of migration (Cade \& Noon 2003). In QR analyses, the dataset consists of counts of birds associated with a given (Julian) date. QR is a particular type of regression analysis that results in estimates that approximate the conditional median and other quantiles (instead of the conditional mean as in the traditional regression analysis) of the response variable given certain values of the predictor variables. This is done by minimizing a sum of weighted absolute errors rather than the sum of squared errors. In particular, QR allows heterogeneity in the error distribution fitting a specific regression quantile by minimizing a sum of weighted absolute errors. This makes it attractive for modelling the timing of bird migration in which different quantiles may represent different population segments (Knudsen et al. 2007). As a final output, QR coefficients provide for each percentile a measure of the estimation of the yearly rate of change during the considered time period (Cade \& Noon 2003, Tøttrup et al. 2006).

We tested for the presence of significant phenological shifts in the 10th, 50th and 90th percentiles of the migratory passage, with the aim of accounting for possible intra-specific differences in the phenological shift (Lehikoinen et al. 2004, Møller \& Merilä 2004, Knudsen et al. 2007, Filippi-Codaccioni et al. 2010). Non-reproductive individuals and failed breeders tend to leave their summer ranges earlier than successful breeders (Newton 2008) and nonbreeders contain a greater proportion of immature birds (Newton 1979). We considered the 10th quantile to be representative of the passage of immature (2nd and 3rd calendar year birds) and non-breeding adult individuals. The central part of migration (i.e. median or 50th quantile) was assumed to be the value of the main migratory flow (Filippi-Codaccioni et al. 2010) and to be representative of the behaviour of the bulk of the breeding adult cohort. The 90th quantile was assumed to be representative of the migratory date of the later individuals, which in many species of birds are almost exclusively juveniles on their first migration (Kjellén 1992).

For most of the species studied, this association of age classes with different timing of migration 
was consistent with field observations (Programa Migres 2009). However, this phenological pattern is different for a few of the studied species, including juvenile White Storks Ciconia ciconia, and Eurasian Sparrowhawks Accipiter nisus, which migrate ahead of adults (Kjellén 1992, Fernández-Cruz 2005). To investigate species-specific shifts in phenology (i.e. QR coefficients) we used variables related to the ecological and life-history traits in linear regression models where the regression coefficients from the QR analysis were used as dependent variables.

\section{Predictors of phenological shifts}

We selected a set of ecological, morphological, abundance and life-history traits as predictors that may affect the phenological shift of autumn migration.

Breeding population trends (ordered categorical variable) were obtained from estimates of European population trends of breeding birds during 1990-2000 using an assessment by BirdLife International (2004) on a 7-point scale, from large decline $(-3)$ to large increase $(+3)$.

The trend of migration counts (continuous variable) was measured as the slope of regression models fitted to the time series of each species' count data. Based on the observed linear patterns of counts over time, we used linear regression using annual counts as the dependent variable. A Shapiro-Wilk test was run prior to regression to check for normal distribution of data (Fowler \& Cohen 1992) and the validity of the linear adjustment; data were all normally distributed. Migration counts reflect not only trends in the numbers of breeding birds but also in the numbers of immature and floater non-breeding individuals. We considered this trend in the analysis to evaluate a possible relationship between recent overall population trends (breeding and non-breeding individuals) with the shifts in phenology.

Breeding population size (continuous variable) was taken as the European breeding population size estimates for each species from BirdLife International (2004). Larger populations may give rise to a larger number of heterozygous loci, which may facilitate phenological response to climate change (Møller et al. 2008).

Northernmost breeding latitude (continuous variable) was measured from the EBCC atlas of European breeding birds (Hagemeijer \& Blair 1997). Timing of migration is affected by the latitudinal location of the breeding population. We included this variable in order to look for differences related to the different breeding spatial range among species.

Body mass (continuous variable) was taken from Bruderer and Boldt (2001).

Mean clutch size (continuous variable) was taken from Cramp and Simmons (1980) and Ferguson-Lees and Christie (2001).

Duration of the breeding period (continuous variable) was taken as the number of days typically required for successful breeding from egg-laying to fledging (from Cramp \& Simmons 1980, FergusonLees \& Christie 2001).

Generation length (continuous variable) was considered a proxy for life expectancy. Generation length was defined, according to BirdLife International (2004), as 'the average age of the parents of the current cohort (i.e. newborn individuals in the population)' and it was calculated as:

$$
\mathrm{GL}=((2-m) / 2 m)+b
$$

where $m$ is the mean age of adult mortality for the species in a stable population and $b$ is the mean age of first reproduction in a stable population.

Habitat specialization (categorical variable) was taken as the degree of ecological specialization from appendix 4 of BirdLife International (2004) according to the Tucker and Evans (1997) classification. We assigned a value of 1 to species that are strictly linked to a particular habitat and a value of 0 to species living in more than one type of habitat. We predict that specialist species would be less prone to change their passage dates than would be more generalist species with greater adaptive and/or plastic capabilities (Begon et al. 2006).

\section{Phylogenetic models}

We built a phylogenetic tree representing the evolutionary relationships among the set of 11 species following the suggestions of Rubolini et al. (2015). Specifically, we downloaded 3000 trees from birdtree.org based on the Hackett full dataset (Jetz et al. 2012) and computed a consensus tree over this set of phylogenies using the script given in Rubolini et al. (2015) for the library DendroPy of Python (Sukumaran \& Holder 2010). This script computes a consensus based on the 50\% majority rule and calculates mean branch lengths. The final tree is represented in Fig. S1. Successively, we ran phylogenetically corrected linear models to test 
whether any of the above-mentioned factors influenced the phenological shift of the autumn migration in the 11 species. For this analysis we used the package phylolm (Ho \& Ané 2014) for R 3.1.2 (R Development Core Team 2006), with Pagel's lambda as the evolutionary model (see phylolm manual for details). We used the variance inflation factor (library HH for R 3.1.2, Heiberger 2015) to test for collinearity of the predictors entered simultaneously in the statistical models. We excluded clutch size from the predictor set because of its collinearity with other factors. Finally, for each of the three quantiles (10th, 50th and 90th), we calculated all of the 64 possible combinations of models using the set of the remaining six predictors. We ordered these by increasing the adjusted Akaike information criterion (AICc) value, and retained as the best supported models those with $\triangle$ AICc less than 2 (IT approach; Symonds \& Moussalli 2011). In cases where more than a single model was selected following this procedure (those with $\triangle \mathrm{AICc}<2$ ), we reported and considered in the results the entire set of equivalent models.

\section{Pyrenees meta-analysis}

We performed analogous phylogenetically corrected analyses for the species reported by FilippiCodaccioni et al. (2010) using the same predictors as above and, as a dependent variable, the phenological shift corresponding to the 50th percentile reported from the Organbidexka watchsite between 1981 and 2008 by Filippi-Codaccioni et al. (2010). Because the set of species studied by Filippi-Codaccioni et al. (2010) differs slightly from that used in our main analyses, we computed a specific phylogenetic tree to run this test following the procedure described above (Fig. S2).

\section{RESULTS}

Autumn migratory dates across the Strait of Gibraltar shifted significantly in ways that varied in magnitude and direction among migration phases and species. As a general pattern, there was a greater shift in the early phases compared with the late phases of the migration (Fig. 2). Specifically, there was a significant and consistent advance in autumn migration dates for all the migration phases (10th, 50th and 90th quantiles) of Montagu's Harrier Circus pygargus and Eurasian Sparrowhawk. We also identified significant advances in migration dates in the 10th and 50th quantiles for Western Marsh Harrier Circus aeruginosus and Booted Eagle Hieraaetus pennatus. In contrast, there was stability in the migration dates of European Honey Buzzard Pernis apivorus for all migration phases assessed. Shifts in the timing of migration in the remaining species were not consistent among migration phases, with some phases advancing, others keeping stable, and others even showing later passage dates (Fig. 2, Table S1).

Phylogenetically corrected linear models showed that population trend was the main variable related to the variation in phenological shifts of autumn migration. In general, species that experienced the largest positive population trends over the last decades showed the greatest advances in their autumn migratory dates (Table 1, Table S2). This effect emerged as being the only factor retained in the best-selected model for the bulk of the migration (50th quantile). Population trend had a less important but also significant effect at the beginning (10th quartile) and at the tail end

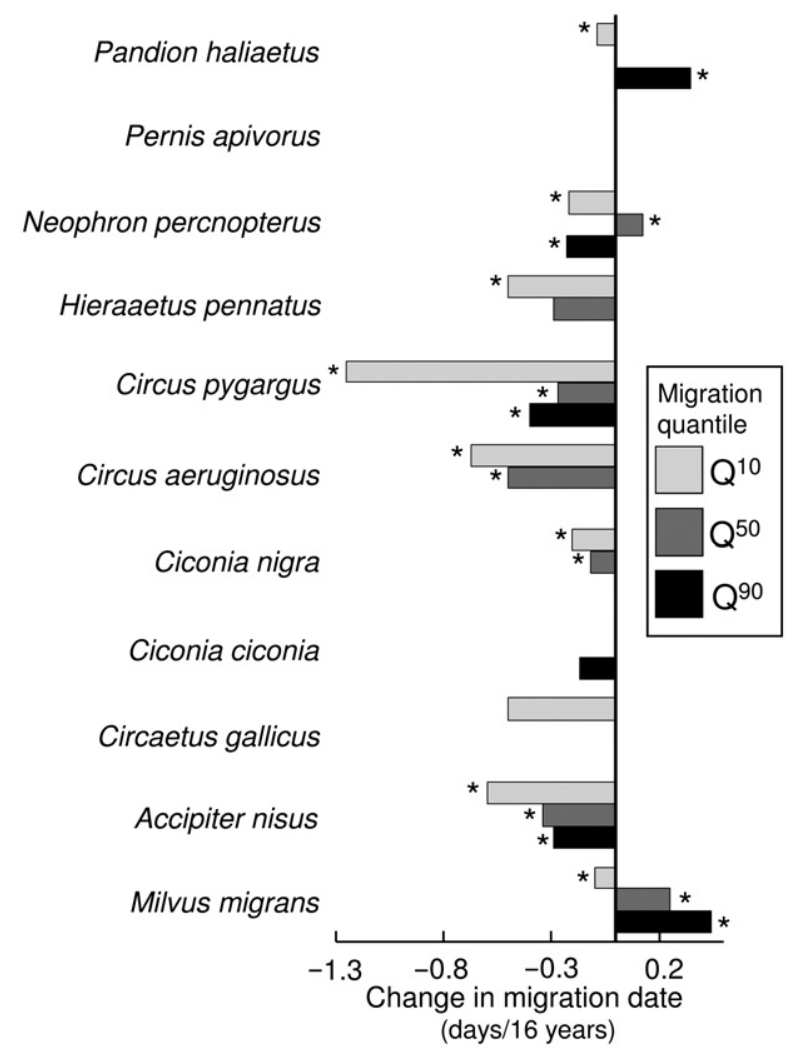

Figure 2. Shifts in autumn migration dates of 11 species of soaring birds at the Strait of Gibraltar between 1999 and 2014. Different shading indicates the different quantile of the migration: grey $=Q^{10}$, the first $10 \%$ of the migration; dark grey $=Q^{50}$, median; black $=Q^{90}$, tail. 
Table 1. Model selection of the phylogenetically corrected linear models testing the factors affecting interspecific variation of the migratory phenology of soaring birds at the Strait of Gibraltar between 1999 and 2014. Factors considered were: population trend (POPTREND); length of the breeding season (BREED_LENGTH); trends of migration counts (COUNTS); northernmost breeding latitudes (NORTH_LAT); body mass (MASS) and habitat specialism (SPECIALIST). For each phase of the migration, expressed by the different quantiles $(Q)$, the set of the equivalent best models as well as the first excluded model are presented. Model parameters are shown in Table S1.

\begin{tabular}{|c|c|c|c|c|c|}
\hline Parameter & Ord & Model & $\mathrm{AICc}$ & $\Delta \mathrm{AICc}$ & AIC weights \\
\hline \multirow[t]{5}{*}{ Onset $\left(Q^{10}\right)$} & 1 & null model & 18.182 & 0 & 0.299 \\
\hline & 2 & MASS & 18.937 & 0.755 & 0.197 \\
\hline & 3 & COUNTS & 19.653 & 1.471 & 0.138 \\
\hline & 4 & COUNTS+POPTREND & 19.834 & 1.653 & 0.126 \\
\hline & 5 & POPTREND & 21.288 & 3.106 & 0.061 \\
\hline \multirow[t]{3}{*}{ Midpoint $\left(Q^{50}\right)$} & 1 & POPTREND & 5.372 & 0 & 0.434 \\
\hline & 2 & null model & 6.504 & 1.312 & 0.246 \\
\hline & 3 & MASS+POPTREND & 9.499 & 4.127 & 0.055 \\
\hline \multirow[t]{2}{*}{ End $\left(Q^{90}\right)$} & 1 & null model & 9.122 & 0 & 0.627 \\
\hline & 2 & POPTREND & 13.462 & 4.339 & 0.072 \\
\hline
\end{tabular}

(90th quartile) of the migration distribution. We found a significant effect of migration counts on the 10th quantile (the most abundant species advanced the earliest), which became significant only if considered in association with population trend. Moreover, there was a non-significant positive effect of body mass on phenology for the same quantile (smaller species advanced the most). Other factors such as length of the breeding season, northernmost breeding latitude and habitat specialism had no major effect on the interspecific variation of phenological shift of migratory dates.

\section{Pyrenees meta-analysis}

The phylogenetically corrected analyses on the Pyrenees dataset showed that the studied species exhibiting a positive population trends in 19902000 also tended to advance their autumn migratory date through the Pyrenees at a greater rate (Fig. 3, Table 2), although this relationship was not statistically significant (Table S2). For the Pyreneés, in contrast to what we observed at the Strait, the best predictor of the observed phenological advancement was the trend in migration counts, so that species for which populations increased most during the study period also showed the greatest advance in their autumn migratory date (Table 2).

\section{DISCUSSION}

Our results showed that species of soaring birds migrating across the Strait of Gibraltar have, in general, advanced their autumn central migration dates over the last 16 years. These results are in agreement with the observed advance of autumn migration passage dates of long-distance migrating raptors in the Pyrenees (Filippi-Codaccioni et al. 2010). Therefore, our findings support the existence of a rapid response to climate change through shifts in the migration phenology of long-distance migrants and long-lived soaring birds such as raptors and storks (Scholer et al. 2016). Different rates of change in migration dates were related to population trends at the continental scale rather than to any ecological or behavioural dissimilarity between species.

In accordance with previous studies, the longdistance migrant species reported here have advanced their autumn migration in recent decades, possibly as a consequence of earlier spring arrival (Jenni \& Kéry 2003, Filippi-Codaccioni et al. 2010, Jaffré et al. 2013). Not only is earlier arrival in spring advantageous for migratory birds, it also appears to be advantageous to arrive early on the wintering grounds, particularly for adult individuals, allowing them to choose the best wintering territories and to be more rapidly ready for the subsequent breeding attempt (Kjellén 1992). In addition, earlier departures allow migratory birds to reach the Sahel before the seasonal dry period (Jenni \& Kéry 2003, Zwarts et al. 2009).

Our results show that advances in migration were generalized across species in the earlier phases of migration, whereas the direction of the shifts was less pronounced in later phases. Autumn phenologies of many long-distance species of migratory raptors usually show a higher percentage of 

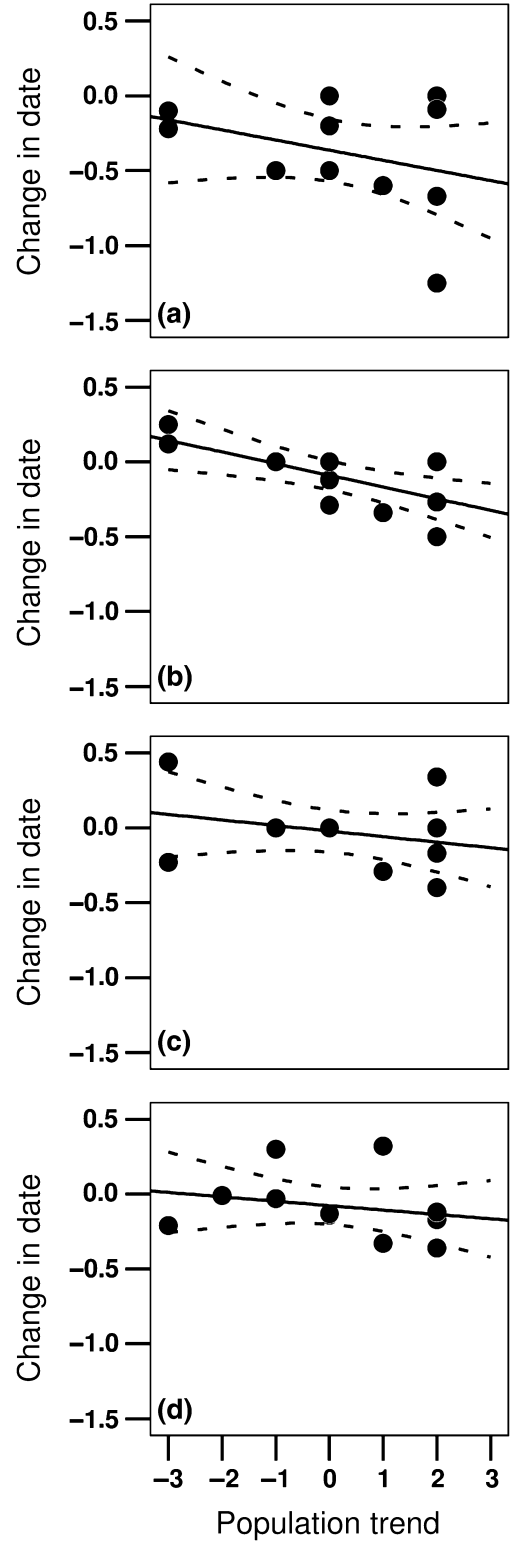

Figure 3. Linear relationships between the shift in autumn migratory dates and population trends. Each dot represents one species. $Q^{10}=$ the first $10 \%$ of the migration; $Q^{50}=$ median; $\mathrm{Q}^{90}=$ tail. (a) 10th Gibraltar; (b) 50th Gibraltar; (c) 90th Gibraltar; (d) 50th Pyrenees. Dashed lines represent 95\% confidence intervals of regression.

juveniles in the last part of the migratory season (Kjellén 1992), including European Honey Buzzard, Montagu's Harrier, Western Marsh Harrier, Short-toed Snake Eagle Circaetus gallicus, Booted Eagle, Black Kite Milvus migrans and Western Osprey Pandion haliaetus (Schifferli 1967, Kjellén 1992, Fransson \& Pettersson 2001, Hake et al. 2003, Agostini et al. 2004, Agostini \& Panuccio
2005, Premuda et al. 2007). In contrast, there are a few species in which juveniles migrate earlier than adult individuals, including Eurasian Sparrowhawk (Kjellén 1992), Black Stork Ciconia nigra (Chevallier et al. 2010) and White Stork (Fernández-Cruz 2005). Thus, our results suggest that the migration of juvenile individuals, mainly at the end of the migratory period, shows more stable phenological trends than that of adults and non-reproductive individuals, which comprise the bulk of birds in the early and middle phases of migration. Adult birds are potential breeding individuals and are therefore more constrained by the timing of breeding and are probably most in need of adjusting their timing to climate change. Among adult birds, the first part of migration is expected to include a higher percentage of non-reproductive individuals (Newton 2008). Non-breeding birds that are not constrained by the time of breeding may leave summer territories earlier than individuals that were successful in reproduction (Alerstam 1990) and take advantage of reaching their wintering grounds earlier (see above). On the other hand, juvenile birds undertaking their first migration cannot adjust their migration dates because they are inexperienced and are pushed south by the changing photoperiod, but also because they need to fledge and gain strength before starting the migration (Newton 2008). This age-dependent behaviour may explain why individuals moving at the end of the migration period (most probably juvenile birds) showed more stable phenological trends or even delays in the dates of passage. Overall, migration shifts in relation to climate change appear to vary among migration phases, indicating different responses to different ecological pressures for different groups of individuals (i.e. age classes and/or breeding populations).

According to our results, the migration of small body-sized species is probably more sensitive to climate change. It is known that birds with larger body size have lower metabolic rates and store more energy per unit of body weight, increasing their survival rates during adverse conditions (Newton 1998). Larger body size is also, in most cases, an indicator of greater fat reserves. Thus, species with smaller body mass may be more conditioned by temperature than larger birds are, because of the difference in thermoregulatory costs (Dunn 2004, Cox 2010). From this perspective, smaller species could be forced to respond more rapidly to climate change compared with largersized birds. 
Table 2. Model selection of the phylogenetically corrected linear models testing the factors affecting interspecific variation of the migratory phenology of soaring birds at the Pyrenees between 1981 and 2008 (data from Filippi-Codaccioni et al. 2010). The set of the equivalent best models as well as the first excluded model are presented. Model parameters are shown in Table S1.

\begin{tabular}{lccccc}
\hline Parameter & Ord & Model & AICc & AAICc & AIC weights \\
\hline Midpoint $\left(\mathrm{Q}^{50}\right)$ & 1 & COUNTS & 5.667 & 0 & 0.395 \\
& 2 & null model & 6.318 & 0.648 & 0.285 \\
& 3 & POPTREND+COUNT & 9.639 & 3.969 & 0.054 \\
\hline
\end{tabular}

Our results confirm previous findings (Møller et al. 2008, Saino et al. 2011) that species of birds that are responding to climate change by changing their migratory dates are not declining, whereas species without shifts in their migration timing show a decline of their breeding populations in Europe. Using the same methodology, reanalysis of long-term migratory date changes of soaring birds in the Pyrenees confirms the negative relationship between population trend and magnitude of autumn phenological shift.

At both Gibraltar (only in the early phase) and the Pyrenees, trends in the number of counted raptors at the site influenced dates of migration. Raptor counts show great season-to-season variability that is often intrinsic to the migration itself, being influenced by factors such as weather conditions at the site and along the flyway (Bildstein et al. 2007, Miller et al. 2016, Scholer et al. 2016).

\section{Changing migratory dates as a result of phenotypic plasticity}

Most of the birds considered here are long-lived species and our study period is only 16 years (Cramp \& Simmons 1980). As rates of adaptive evolution may be very slow in long-lived organisms with overlapping generations (Pulido \& Berthold 2004,2010 ), we can predict that this change in behaviour is unlikely to be the result of genotypic changes. Thus, birds facing short-term environmental changes could adjust their ecological behaviour through phenotypic plasticity that would allow individuals to cope with a changing environment (Nussey et al. 2007, Pulido 2007, Jaffré et al. 2013, Scholer et al. 2016). While evidence for genetic adaptation to climate change is found in some systems, demonstrated examples of genetic adaptation are still scarce (Charmantier \& Gienapp 2014, Merilä \& Hendry 2014). Few papers are available for the comparison of genetic and behavioural features in explaining the migratory tendency of birds. However, theoretical models suggest a major contribution of phenotypic plasticity in determining changes of migratory behaviour in long-lived non-passerines (Ogonowski \& Conway 2009, Morganti 2015) and it is assumed to be enough to explain the shifts in timing (Charmantier et al. 2008, Knudsen et al. 2011).

In our case study, the later part of migration (during which higher percentages of juveniles migrate) is in general more stable. Experienced individuals differ from juveniles that are pushed south, possibly by endogenous rhythms (Gwinner 1996, Dawson et al. 2001, Martín et al. 2016a,b). Older individuals often use their previous experience during migration by showing orientation and navigational abilities and perhaps also adjusting their timing according to previous experiences (Newton 2008, Sergio et al. 2014). It has been observed that under strong selective pressure, passerines could shift the onset of the autumn migration in only two generations due to genetic changes (Pulido \& Berthold 2004, 2010). However, the relative stability of the migration dates of juveniles (90th quantile) which migrate, in most cases, without following adults, is a further suggestion that the observed phenological changes are not the result of a micro-evolutionary process.

\section{CONCLUSIONS}

Our results confirm that long-lived bird species that are changing their migratory dates are those showing positive population trends. Within populations, adult breeding birds are the most constrained in terms of migration timing because of the breeding costs. On the other hand, adult breeding birds may gain the greatest advantage of an earlier departure from the breeding areas and, consequently, of an earlier arrival to the wintering grounds. As the species studied here were mostly long-lived birds, we suggest that the rapid changes observed in the 
migratory dates may result from a phenotypic response to climate warming. Particular ecological and behavioural features of each group have probably shaped the different responses in the autumn migration timing that we found among species and individuals within the same species (i.e. adults and juveniles). Understanding the species- and individual-specific traits modulating the responses to climate change will help us to identify the most sensitive species and populations among breeding European soaring birds. This step is of great importance to develop suitable management and conservation plans for these species under climate change.

Data analysis of this paper was supported by the European Science Foundation through a grant in the field of Eurapmon Network activities. We are grateful to the thousands of people (volunteers and staff) who collected the information presented in this study and to the Board of the Migres Foundation. The data counts from the Strait of Gibraltar analysed in the study were collected within the field monitoring campaigns 1999/2014 funded by grants of the Consejeria de Medio Ambiente from the Junta de Andalucia (Spain). M.M. was funded by Italian Ministry of Education, University and Research (PRIN 2010-2011, 20180 TZKHC). Diego Rubolini gave support with phylogenetic analyses. We also acknowledge Giuseppe Bogliani, Todd Katzner, Jeff Kelly and Rebecca Kimball for their suggestions on earlier drafts of the manuscript as well as Robert A. Miller and Andy Patterson for reviewing the English of the manuscript.

\section{REFERENCES}

Agostini, N. \& Panuccio, M. 2005. Analysis of the spatial migration patterns of adult Honey Buzzards (Pernis apivorus) during Spring and Autumn in the Central Mediterranean. Ring 27: 215-220.

Agostini, N., Baghino, L., Panuccio, M., Premuda, G. \& Provenza, N. 2004. The autumn migration strategies of juvenile and adult Short-toed Eagles (Circaetus gallicus) in the Central Mediterranean. Avocetta 28: 37-40.

Alerstam, T. 1990. Bird Migration. Cambridge: Cambridge University Press.

Begon, M., Townsend, C.R. \& Harper, J.L. 2006. From Individuals to Ecosystems, 4th edn. Oxford: John Wiley \& Sons.

Bildstein, K.L., Smith, J.F. \& Yosef, R. 2007. Migration counts and monitoring. In Bird, D.M. \& Bildstein, K.L. (eds) Raptor Research and Management Techniques: 101-116. Blaine: Hancock House Publisher.

BirdLife International 2004. Birds in Europe: Population Estimates, Trends and Conservation Status. BirdLife Conservation Series No. 12. Cambridge: BirdLife International.

Both, C. 2007. Comment on 'Rapid advance of spring arrival dates in long-distance migratory birds'. Science 315: 598b.
Both, C. \& Marvelde, L.T. 2007. Climate change and timing of avian breeding and migration throughout Europe. Clim. Res. 35: 93-105.

Bruderer, B. \& Boldt, A. 2001. Flight characteristics of birds: I. Radar measurements of speeds. Ibis 143: 178-204.

Cade, B.S. \& Noon, B.R. 2003. A gentle introduction to quantile regression for ecologists. Front. Ecol. Environ. 1: 412-420.

Charmantier, A. \& Gienapp, P. 2014. Climate change and timing of avian breeding and migration: evolutionary versus plastic changes. Evol. Appl. 7: 15-28.

Charmantier, A., McCleery, R.H., Cole, L.R., Perrins, C., Kruuk, L.E.B. \& Sheldon, B.C. 2008. Adaptive phenotypic plasticity in response to climate change in a wild bird population. Science 320: 800-803.

Chevallier, D., Handrich, Y., Georges, G.Y., Baillon, F., Brossault, P., Aurouet, A., Le Maho, Y. \& Massemin, S. 2010. Influence of weather conditions on the flight of migrating black storks. Proc. R. Soc. B 277: 2755-2764.

Cox, G.W. 2010. Bird Migration and Global Change. Washington, DC: Island Press.

Cramp, S. \& Simmons, K.E.L. 1980. The Birds of the Western Palearctic. Oxford: Oxford University Press.

Dawson, A., King, V.M., Bentley, G.E. \& Ball, G.F. 2001. Photoperiodic control of seasonality in birds. J. Biol. Rhythms 16: 365-380.

Dunn, P. 2004. Breeding dates and reproductive performance. Adv. Ecol. Res. 35: 69-87.

Ferguson-Lees, J. \& Christie, D.A. 2001. Raptors of the World. London: Helm.

Fernández-Cruz, M. 2005. La migración otoñal de la Cigüeña Blanca (Ciconia Ciconia) por el estrecho de Gibraltar. In: Molina, B. \& Del Moral, J.C. (eds) La Cigüeña Blanca En España. VI Censo Internacional (2004): 162-201. Madrid: SEO/BirdLife.

Fiedler, W., Bairlein, F. \& Köppen, U. 2004. Using largescale data from ringed birds for the investigation of effects of climate change on migrating birds: pitfalls and prospects. Adv. Ecol. Res. 35: 49-67.

Filippi-Codaccioni, O., Moussus, J.P., Urcun, J.P. \& Jiguet, F. 2010. Advanced departure dates in long-distance migratory raptors. J. Ornithol. 151: 687-694.

Finlayson, C. 1992. Birds of the Strait of Gibraltar. London: T. \& A.D. Poyser.

Fowler, J. \& Cohen, L. 1992. Statistics for Ornithologists. Thetford: BTO.

Fransson, T. \& Pettersson, J. 2001. Svenskringmärkningsatlas, 1st edn. Stockholm: Naturhistoriska Riksmuseet.

Gienapp, P., Teplitsky, C., Alho, J.S., Mills, J.A. \& Merila, J. 2008. Climate change and evolution: disentangling environmental and genetic responses. Mol. Ecol. 17: 167178.

Gordo, O. 2007. Why are bird migration dates shifting? Climate Res. 35: 35-58.

Gwinner, E. 1996. Circadian and circannual programmes in avian migration. J. Exp. Biol. 199: 39-48.

Hagemeijer, E.J.M. \& Blair, M.J. 1997. The EBCC Atlas of European Breeding Birds - Their Distribution and Abundance. London: T. \& A.D. Poyser.

Hake, M., Kjellén, N. \& Alerstam, T. 2003. Age-dependent migration strategy in Honey Buzzards Pernis apivorus tracked by satellite. Oikos 103: 385-396. 
Heiberger, R.M. 2015. HH: Statistical Analysis and Data Display. R package version 3.1-23.

Ho, L.S.T. \& Ané, C. 2014. Package 'Phylolm'- Phylogenetic Linear Regression.

Jaffré, M., Beaugrand, G., Goberville, É., Jiguet, F., Kjellén, N., Troost, G., Dubois, P., Leprêtre, A. \& Luczak, C. 2013. Long-term phenological shifts in raptor migration and climate. PLOS ONE 8: e79112.

Jenni, L. \& Kéry, M. 2003. Timing of autumn bird migration under climate change: advances in long-distance migrants, delays in short-distance migrants. Proc. R. Soc. B270: 467-1471.

Jetz, W., Thomas, G.H., Joy, J.B., Hartmann, K. \& Mooers, A.O. 2012. The global diversity of birds in space and time. Nature 491: 444-448.

Jonzén, N., Linden, A., Ergon, T., Knudsen, E., Vik, J.O., Rubolini, D., Piacentini, D., Brinch, C., Spina, F., Karlsson, L., Stervander, M., Andersson, A., Waldenstrom, J., Lehikoinen, A., Edvardsen, E., Solvang, R. \& Stenseth, N.C. 2006. Rapid advance of spring arrival dates in long-distance migratory birds. Science 312: 1959-1961.

Kjellén, N. 1992. Differential timing of autumn migration between sex and age groups in raptors at Falsterbo, Sweden. Ornis Scand. 23: 420-434.

Klaassen, R.H.G., Strandberg, R., Hake, M., Olofsson, P., Tøttrup, A.P. \& Alerstam, T. 2010. Loop migration in adult Marsh Harrier Circus aeruginosus, as revealed by satellite telemetry. J. Avian Biol. 41: 200-207.

Knudsen, E., Lindén, A., Ergon, T., Jonzén, N., Vik, J.O., Knape, J., Røer, J.E. \& Stenseth, N.C. 2007. Characterizing bird migration phenology using data from standardized monitoring at bird observatory. Climate Res. 35: 59-77.

Knudsen, E., Lindén, A., Both, C., Jonzén, N., Pulido, F., Saino, N., Sutherland, W.J., Bach, L.A., Coppach, T., Ergon, T., Gienapp, P., Gill, J.A., Gordo, O., Hedenstrom, A., Lehikoinen, E., Marra, P.P., Møeller, A.P., Nilsson, A.L.K., Péron, G., Ranta, E., Rubolini, D., Sparks, T.H., Spina, F., Studds, C.E., Saether, S.A., Tryjanowski, P. \& Stenseth, N.C. 2011. Challenging claims in the study of migratory birds and climate change. Biol. Rev. 86: 928-946.

Kokko, A. 1999. Competition for early arrival in migratory birds. J. Anim. Ecol. 68: 940-950.

Lehikoinen, E., Sparks, T.H. \& Zalakevicius, M. 2004. Arrival and departure dates. Adv. Ecol. Res. 35: 1-31.

Limiñana, R., Soutullo, A. \& Urios, V. 2007. Autumn migration of Montagu's Harriers Circus pygargus tracked by satellite telemetry. J. Ornithol. 148: 517-523.

Martín, B., Onrubia, A. \& Ferrer, M. 2014. Effects of climate change on the migration behavior of the Common Buzzard (Buteo buteo). Clim. Res. 60: 187-197.

Martín, B., Onrubia, A., De la Cruz, A. \& Ferrer, M. 2016a. Trends of autumn counts at Iberian migration bottlenecks as a tool for monitoring continental populations of soaring birds in Europe. Biodivers. Conserv. 25: 295.

Martín, B., Onrubia, A. \& Ferrer, M. 2016b. Migration timing responses to climate change differ between adult and juvenile White storks across Western Europe. Clim. Res. 69: 9-23.

Merilä, J. \& Hendry, A.P. 2014. Climate change, adaptation, and phenotypic plasticity: the problem and the evidence. Evol. Appl. 7: 1-14.
Meyburg, B.U., Gallardo, M., Meyburg, C. \& Dimitrova, E. 2004. Migrations and sojourn in Africa of Egyptian Vultures (Neophron percnopterus) tracked by satellite. J. Ornithol. 145: 273-380.

Miller, R.A., Onrubia, A., Martin, B., Kaltenecker, G.S., Carlisle, J.D., Bechard, M.J. \& Ferrer, M. 2016. Local and regional weather patterns influencing post-breeding migration counts of soaring birds at the Strait of Gibraltar, Spain. The Ibis 158: 106-115.

Miller-Rushing, A.J., Lloyd-Evans, T.L., Primack, R.B. \& Satzinger, P. 2008. Bird migration times, climate change, and changing population sizes. Global Change Biol. 14: 1959-1972.

Møller, A.P. 2007. Tardy females, impatient males: protandry and divergent selection on arrival date in the two sexes of the Barn Swallow. Behav. Ecol. Sociobiol. 61: $1311-1319$.

Møller, A.P. \& Fiedler, W. 2010. Long-term time series of ornithological data. In Møller, A.P., Fiedler, W. \& Berthold, P. (eds) Effects of Climate Change on Birds: 33-38. Oxford: Oxford University Press.

Møller, A.P. \& Merilä, J. 2004. Analysis and interpretation of long-term studies investigating responses to climate change. Adv. Ecol. Res. 35: 111-130.

Møller, A.P., Rubolini, D. \& Lehikoinen, E. 2008. Populations of migratory bird species that did not show a phenological response to climate change are declining. Proc. Natl Acad. Sci. USA 105: 16195-16200.

Morganti, M. 2015. Birds facing climate change: a qualitative model for the adaptive potential of migratory behaviour. Riv. Ital. Ornitol. 85: 3-13.

Newton, I. 1979. Population Ecology of Raptors. London: T. \& A.D. Poyser.

Newton, I. 1998. Population Limitation in Birds. London: Academic Press.

Newton, I. 2008. The Migration Ecology of Birds. London: Academic Press.

Nussey, D.H., Wilson, A.J. \& Brommer, J.E. 2007. The evolutionary ecology of individual phenotypic plasticity in wild populations. J. Evol. Biol. 20: 831-844.

Ogonowski, M.S. \& Conway, C.J. 2009. Migratory decisions in birds: extent of genetic versus environmental control. Oecologia 161: 199-207.

Panuccio, M., Agostini, N., Mellone, U. \& Bogliani, G. 2014. Circannual variation in movement patterns of the Black Kite (Milvus migrans migrans): a review. Ethol. Ecol. Evol. 26: 1-18.

Parmesan, C. \& Yohe, G. 2003. A globally coherent fingerprint of climate change impacts across natural systems. Nature 421: 37-42.

Porter, R.F. \& Beaman, M.E.S. 1985. A resumé of raptor migration in Europe and the Middle East. In: Newton, I. \& Chancellor, R.D. (eds) Conservation Studies on Raptors. 237-242. Cambridge: International Council for Bird Preservation Tech. Publ. No. 5.

Premuda, G., Baghino, L., Guillosson, T., Jardin, M., Tirado, M. \& Esteller, V. 2007. A remarkable case of circuitous autumn migration of the Booted Eagles Hieraaetus pennatus through the western and central Mediterranean. Ardeola 54: 349-357.

Programa Migres 2009. Seguimento de la migración de lasaves en el Estrecho de Gibraltar: resultados del Programa Migres 2008. Migres 1: 83-101. 
Pulido, F. 2007. Phenotypic changes in spring arrival: evolution, phenotypic plasticity, effects of weather and condition. Clim. Res. 35: 5-23.

Pulido, F. \& Berthold, P. 2004. Microevolutionary response to climatic change. Adv. Ecol. Res. 35: 151-183.

Pulido, F. \& Berthold, P. 2010. Current selection for lower migratory activity will drive the evolution of residency in a migratory bird population. Proc. Natl Acad. Sci. USA 107: 7341-7346.

R Development Core Team 2006. R, A Language and Environment for Statistical Computing. Vienna: R Foundation for Statistical Computing. http://www.Rproject.org

Rubolini, D., Møller, A.P., Rainio, K. \& Lehikoinen, E. 2007. Intraspecific consistency and geographic variability in temporal trends of spring migration phenology among European bird species. Clim. Res. 35: 135-146.

Rubolini, D., Liker, A., Garamszegi, L.Z., Møller, A.P. \& Saino, N. 2015. Using the BirdTree.org website to obtain robust phylogenies for avian comparative studies: a primer. Curr. Zool. 61: 959-965.

Saino, N., Ambrosini, R., Rubolini, D., Von Hardenberg, J., Provenzale, A., Huppop, K., Huppop, O., Lehikoinen, A., Lehikoinen, E., Rainio, K., Romano, M. \& Sokolov, L. 2011. Climate warming, ecological mismatch at arrival and population decline in migratory birds. Proc. $R$. Soc. B 278: 835-842.

Schaefer, H.C., Jetz, W. \& Böhning-Gaese, K. 2008. Impact of climate change on migratory birds: community reassembly versus adaptation. Global Ecol. Biogeogr. 17: 38-49.

Schifferli, A. 1967. Vom Zug Schweizerischer und Deutscher Schwarzer Milanenach Ringfunden. Orn. Beob. 64: 34-51.

Scholer, M.N., Martín, B., Ferrer, M., Onrubia, A., Bechard, M.J., Kaltenecker, G.S. \& Carlisle, J.D. 2016. Variable shifts in the autumn migration phenology of soaring birds in southern Spain. Ardea 104: 83-93.

Sergio, F., Tanferna, A., De Stephanis, R., Jiménez, L.L., Blas, J., Tavecchia, G., Preatoni, D. \& Hiraldo, F. 2014. Individual improvements and selective mortality shape lifelong migratory performance. Nature 515: 410-413.

Sukumaran, J. \& Holder, M.T. 2010. DendroPy: a python library for phylogenetic computing. Bioinformatics 26: 1569 1571.

Symonds, M.R. \& Moussalli, A. 2011. A brief guide to model selection, multimodel inference and model averaging in behavioural ecology using Akaike's information criterion. Behav. Ecol. Sociobiol. 65: 13-21.

Tøttrup, A.P., Thorup, K. \& Rahbek, C. 2006. Changes in timing of autumn migration in North European songbird populations. Ardea 94: 527-536.
Tucker, G.M. \& Evans, M.I. 1997. Habitats for Birds in Europe: a Conservation Strategy for the Wider Environment. BirdLife Conservation Series no. 6. Cambridge: BirdLife International.

Visser, M.E., Perdeck, A.C., van Balen, J.H. \& Both, C. 2009. Climate change leads to decreasing bird migration distances. Global Change Biol. 15: 1859-1865.

Zwarts, L., Bijlsma, R.G., van der Kamp, J. \& Wymenga, E. 2009. Living on the Edge: Wetlands and Birds in a Changing Sahel. Zeist: KNNV Publishing.

$$
\begin{aligned}
& \text { Received } 7 \text { April 2015; } \\
& \text { revision accepted } 1 \text { October } 2016 . \\
& \text { Associate Editor: Jeff Kelly. }
\end{aligned}
$$

\section{SUPPORTING INFORMATION}

Additional Supporting Information may be found in the online version of this article:

Figure S1. Phylogeny of the species used in the analysis of data from the Strait of Gibraltar, as obtained from a consensus tree performed over 3000 alternative trees. Numbers indicate bootstrap values of the consensus tree, which in this case are always 100 because of the well-known phylogenetic relationships among species.

Figure S2. Phylogeny of the species used in the analysis of data from the Pyrenees, as obtained from a consensus tree performed over 3000 alternative trees. Numbers indicate bootstrap values of the consensus tree, which in this case are always 100 because of the well-known phylogenetic relationships among species.

Table S1. Annual median dates of the daily autumn migration distribution over the Strait of Gibraltar from 1999 to 2014.

Table S2. Estimates along with standard errors of the factors in the best equivalent phylogentic models testing which factors affected phenological shift of migration in a set of soaring species at Gibraltar and Pyrenees (see main text for details). Bold numbers show statistically significant effects. (cf. tables 1 and 2 in main Text). 